\title{
Estudios
}

\section{Derecho al olvido frente a la pena en el derecho penal}

\section{Right to oblivion in relation to the sentence in criminal law}

Oscar David Zabala Puchana ${ }^{1}$

- Recepción: 15/11/2019 A Aprobación: 06/12/2019 • Publicación: 21/05/2020

Para citar este artículo

Zabala Puchana, O. D. (2020). Derecho al olvido frente a la pena en el derecho penal. Dos mil tres mil, 22, e207. https://doi.org/10.35707/dostresmil/22207

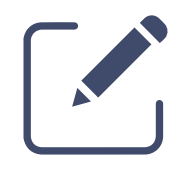

\section{(c) $(1) \Theta \Theta$}

${ }_{1}^{1}$ Programa de Derecho, Universidad de Ibagué, Colombia. ORCID: 0000-0001-8761-8142. Correo electrónico: 5120161130@estudiantesunibague.edu.co 
Resumen. Un aforismo muy famoso dice que el tiempo lo cura todo, pero no es solamente el paso del tiempo el que nos ayuda a superar una situación, sino el mismo olvido, ya que en muchas circunstancias de la vida se vuelve mucho más fácil olvidar que perdonar; ya pertenece a la costumbre social tener una memoria corta en muchas de las situaciones, momentos o vivencias, lo cual hace mucho más fácil vivir en sociedad; sería muy complicado estar recordando cada suceso malo de la vida e intentar olvidarlo para que no sea una carga. Lo anterior no solo en el aspecto personal, sino en el social, porque el no hacerlo genera situaciones catastróficas y perjudiciales para el avance de un conglomerado y un desarrollo en comunidad.

Abstract. A very famous aphorism says that time heals everything. However, it is not only the passage of time that helps us to overcome a situation, but also the oblivion itself; since in many circumstances of life it becomes much easier to forget than to forgive. It already belongs to the social custom of having a short memory in many of the situations, moments or experiences, which makes it much easier to live in society. It would be very difficult to constantly remember every bad event in life and try to forget it so that it is not a burden. The above is applicable to the personal aspect, as well as the social one; because failure to do so can result in catastrophic and harmful situations for the advance of a cluster and the development in community.

\section{Palabras claves}

Derecho al olvido, pena, Estado, habeas data, derechos fundamentales, amnistía, indulto, finalismo penal, funcionalismo penal, revictimización, antecedentes judiciales.

Key words

Right to oblivion, sentence, state, habeas data, fundamental rights, amnesty, pardon, criminal finalism, criminal functionalism, revictimization, criminal record. 


\section{Introducción}

Es tan importante "olvidar" y tener en cuenta lo crucial que se vuelve hablar de una "sociedad sin memoria”, por ello podríamos preguntarnos: ¿Es solo un paradigma social?, o ¿existe una institución que se encargue de coaccionar el olvido? Después de una extensa legislación con muchos matices y arreglos, encontramos que el Derecho, ese conjunto de normas que rige la conducta humana en el afán de regular todas las relaciones, instaura el denominado "Derecho al olvido", una garantía de normas y principios que brindan la potestad de olvidar alguna información en específico, que si bien, en su momento generó cierta importancia, ahora solo afecta al individuo al tener dicha información en la red.

¿A quién alguna vez en la vida no le gustaría borrar algo vergonzoso que está en las redes sociales? Una pregunta que se responde de manera afirmativa, no por ocultar algo malo, sino porque el factor más recurrente es la irresponsabilidad al momento del uso de las redes sociales. Frente a esta problemática y con esta premisa nace el llamado "Derecho al olvido"; una institución que se desarrolla principalmente dentro del "Habeas data", y después ha transigido a todo el Derecho. Básicamente, si existe una información publicada en internet que no sea importante por el paso del tiempo o que sea negativa para la persona, esta pueda ser borrada o dejarse oculta. Al respecto, Pere Simón Castellano, citado por Platero (2016), dice que el derecho al olvido es "una forma poética de referirse principalmente al derecho de cancelación, y eventualmente también al de oposición, en el marco del derecho fundamental de la protección de datos" (p. 249). En contexto, se puede afirmar que el concepto mismo no nace en nuestro ordenamiento jurídico, sino que proviene de la Unión Europea, y se comienza a trasladar a todos los demás ordenamientos.

Diferente a cualquier otro desarrollo jurídico, el derecho al olvido tiene formas distintas de evolucionar dependiendo el país y la tradición jurídica; es decir, no en todos los lugares se avanza de la misma manera, ya sea por el mismo ordenamiento jurídico y sus normas, que impiden una plenitud del derecho o simplemente porque no se necesita, sin perjuicio de que la proliferación de este derecho sea innegable y llegue a todos los ordenamientos; aquello que no ocurre es una suficiente madurez legal para catalogarlo como un derecho de "alto rango" o "primordial".

\section{Desarrollo histórico}

Podemos considerar dos desarrollos históricos del derecho al olvido; uno como concepto y otro como institución frente a todos los desarrollos jurisprudenciales, legales y doctrinales del derecho comparado; el primero más arcaico y de unión de muchos vestigios históricos que suceden en toda la cronología del hombre moderno, y el segundo más técnico y con un concepto definido y sustentado. Esto no implica que se deben asumir dos avances históricos distintos, sino que es una muestra de cómo dicho avance no ha sido integral y ha tenido nombres diferentes, pero que en esencia adquieren las mismas características jurídicas para que al final desencadene con una decisión bien sea judicial o legal: una información en redes o en una fuente; el agravio o la 
violación de un derecho que nace por la publicación del mismo y la exigencia de que se respete ese derecho.

\section{Desarrollo histórico conceptual}

El desarrollo histórico del derecho al olvido como concepto arcaico, va muy ligado a hechos históricos concomitantes a la terminación de la prehistoria y la consolidación de la escritura como método de conservación de la información y trasmisión de costumbres, creencias e historias, que ayudan a crear una identidad de la sociedad; por lo tanto, no encontraremos vestigios del derecho al olvido antes de la prehistoria, porque la información se encamina como concepto cuando esta se comienza a conservar.

El primer hecho histórico ocurre en el antiguo Egipto, en donde era muy común que al llegar un nuevo faraón, este trataba de eliminar de manera discrecional alguna información que no le era favorable o le generaba disgusto. Según José Padró (1999), en el imperio nuevo, en el siglo XIV a. C. aproximadamente, llamado por los historiadores como el "Periodo de amarna", Amenhotep IV sucede en el trono al padre del mismo nombre Amenhotep III, pero este decide que el imperio debe seguir una cultura religiosa monoteísta, en la que el dios Atón sería el único, y toma represalias contra las otras imágenes y sobre todo información de las demás divinidades, como templos, escritos en papiro o en piedra, y principalmente información del nombre de los otros dioses, lo cual logra una supresión. Luego ocurre de nuevo ese intento por borrar información específica de una deidad, al pasar de Anón a Akenathon, un faraón importante para la arqueología de esa época y que es Tutankamon. Estos acontecimientos nos ayudan a entender cómo esos prospectos de Estados ya ejercían el poder de eliminar información que creían que era o no importante.

El Derecho Romano para muchos historiadores es la cuna de diferentes instituciones que perduran en la contemporaneidad, en la que el derecho al olvido no es la excepción. La concepción de Estado en Roma era sinónimo de controlar, suprimir o borrar cierta información para que sea olvidada. Esta era una práctica común en un estamento totalmente burocrático, a tal punto que se volvió una herramienta que brindaba la posibilidad de suprimir información contraria a los pensamientos e ideología del imperio, dependiendo su época.

La Damnatio memoriae es una figura del Derecho Romano, en la que si el emperador la aprobaba, se buscaba borrar toda información de algún "enemigo del Estado", para que no existiera recuerdo alguno sobre él. Este enemigo podría ser una persona que cometiera infracciones o agravios a la Ley o simplemente no estaba acorde a los preceptos de la máxima autoridad. Sin embargo, al respecto Benoir (2010), citado por David Ros, matiza que:

En realidad, la damnatio memoriae no consiste en suprimir el recuerdo de un personaje histórico de la memoria de sus conciudadanos, sino en privar al mismo de las formas públicas de celebración de su recuerdo. También debemos hacer una precisión inicial de orden jurídico: casi todas las fuentes jurídicas en las que aparece la locución damnatio memoriae o memoria damnata son de época postclásica 
o bien se atribuyen a juristas del último periodo clásico; en época republicana no existe, en puridad, la pena de damnatio memoriae en sentido técnico, sino una serie de medidas que pueden adoptarse in memoriam.

La damnatio memoriae consiste habitualmente en la destrucción de todas las representaciones materiales del damnatus, ya se trate de estatuas, pinturas o relieves de monedas. Pero, además de eliminar su imagen, se suprime también su nombre, para condenarlo así al olvido. En la base de esta práctica está la creencia de que, mediante la pronunciación del nombre, el difunto se mantiene de algún modo vivo en el recuerdo [...]; en cambio, silenciar su nombre es un modo de infligirle un daño eterno. Esta idea aparece abundantemente documentada en la epigrafía funeraria, uno de cuyos principales tópicos es la alocución al caminante para que se detenga y lea la inscripción (consiste et lege). (Ros, 2015, p. 403-404-405).

Roma enriqueció el derecho latino, al otorgarle tantas figuras que ampliaban, codificaban y lograban que la conducta humana se regulara en ciertos patrones; sin embargo, con respecto al olvido, no avanzó y el Estado siguió teniendo el poder de tomar la decisión de desaparecer o no la información. Se pueden encontrar varias teorías para plantear esta problemática, pero la más acertada sería que la soberanía estaba en cabeza del emperador mismo, la potestad de crear derecho era única y exclusivamente de la máxima autoridad, por lo cual no se podía cambiar ese designio.

Luego llega la Edad Media, en la que podemos observar que fue la época en la que se borró más información y se trató de ocultar los nombres de las personas influyentes, pero que estaban en contra de los dogmas y pensamientos de la Iglesia; casos como las Cruzadas o la Inquisición, demostraron que la Iglesia tenía el derecho a hacer olvidar las cosas de las personas, desapareciendo el recuerdo de estas; al fin y al cabo, no se va el que se muere, sino el que se olvida y la Iglesia supo hacerlo de manera adecuada.

A medida que termina la Edad Media y llega la Edad Moderna, podemos encontrar que se vuelve más complicado suprimir información porque avanzan los mecanismos y herramientas para difundirlas; por lo tanto, ese derecho al olvido se fue perdiendo de su titular, que era el Estado y este, para entonces, no fue eficaz para quitar del pensamiento cotidiano algún estigma o precepto.

En ese progreso como concepto del derecho al olvido, se puede ver que no hay un avance coyuntural para cambiar algo que existía, sino una concepción arcaica que, si bien no está a plenitud, sí es una fragmentación. No queda corto reconocer esto, compilado de normas antiguas que han dado el reconocimiento de un derecho que en contraposición no pertenece a los intereses claros de las personas, pues ayudó a reunir y codificar un precedente histórico para que después se pueda llegar a una evolución del mismo.

\subsection{Desarrollo institucional}

En este punto llegamos a la definición conceptual, ahora se entra al impoluto concepto institucional que nace en la conceptualización jurisprudencial y que se desarrolla en pro de la 
protección de otros derechos, de igual o mejor jerarquización, dependiendo del ordenamiento jurídico que se trate o se investigue. La definición no es igual en todos los ordenamientos, es complicado acoplarlo en uno solo, por eso se hace el recuento de los más importantes precedentes que terminan ofreciendo el concepto, que será reconocido después por el Tribunal Europeo como el "Derecho a poder olvidar".

En Italia, al seguir la investigación de Francisco Leturia (2016), quien cita una sentencia de casación italiana, encontramos:

[...] el derecho al olvido ya era mencionado en una sentencia en 1958. Cuatro décadas más tarde, se reconocía en forma expresa refiriéndose al 'al justo interés de cada individuo de no estar indefinidamente expuesto a datos que afectan negativamente su honor o reputación, relativa a la reiterada publicación de una noticia del pasado. (Leturia, 2016, p. 94).

De la cita observamos que desde mediados del siglo xx ya podíamos hablar de un precedente jurisprudencial que reclama el derecho de una persona para que, si hay una noticia que no le guste, la pueda retirar; al tener en cuenta dicho contexto, la información que se retiraba era la que se difundía en la radio o el periódico, medios de comunicación que tienen su apogeo en Italia después de la Segunda Guerra Mundial, al terminarse el Fascismo.

Al saltar a otro sistema con una madurez legislativa distinta a la estadounidense, nutrido y visualizado en el common law, se desarrolla un caso contrario, toda vez que era más importante la primera enmienda de su Carta Magna frente a cualquier otro derecho. Un caso supremamente importante para avanzar en el pensamiento de la justicia de los Estados Unidos acerca de suprimir información, fue el de Jenkins vs. Dell Publisher Company, en el cual ocurrieron unos crímenes en una familia; ellos, para facilitar la resolución del caso, suministraron notas e información periodística que luego la empresa de publicidad convirtió en un libro. Frente a esto, la familia pidió que se retirara dicha información, y por ello el Tribunal Supremo Federal (1956) responde a esa moción:

Suponemos, como afirman los demandantes, que la revista Front Page Detective se publica principalmente con fines de entretenimiento y no tiene como objetivo principal informar al público lector. Como su nombre lo indicaría, está dedicado principalmente a historias de crímenes. (Tribunal Supremo Federal, 1956, s. p.).

Cabe resaltar, la facilidad del Tribunal de salir del paso para no proteger los derechos a la intimidad, al argumentar que no tiene relación un evento o un suceso real con algo que es entretenimiento. Otro caso en el que prevaleció el derecho a la información en vez del derecho a olvidar esta y rehacer la vida, fue el de Cox Broadcasting Corp. vs. Cohn (1973); este tiene relevancia porque se ven involucrados unos gigantes mediáticos contra un grupo pequeño, débil jurídicamente hablando, que busca defender un derecho, en esa lucha de un grande con todas las herramientas y un pequeño que se defiende literalmente con las uñas. 
En un pueblo de Georgia, una estudiante de 17 años de edad fue agredida sexualmente. Sin embargo, en el proceso la jueza terminó retirando los cargos, algo que generó un revuelo en su momento, hasta que los implicados se declararon culpables. Contextualizados dichos sucesos, Thomas Wassell, reportero de WSB-TV, tomó la información de la audiencia pública suministrada por el secretario, y concedió un reportaje contando información del caso con los nombres de las personas implicadas, razón por la cual termina con la demanda de Cohn contra la empresa Cox Broadcasting, fundamentada en la Ley de Georgia o la "Ley del escudo", que prohíbe la publicación de información en esos casos. El Tribunal Supremo de Georgia concluye:

Este estatuto está en conflicto con la Primera Enmienda. Creemos que la Asamblea General de Georgia tenía el derecho perfecto de declarar que la víctima de tal crimen no debe ser identificada públicamente por los medios de comunicación. La primera enmienda no es absoluta; y consideramos que este estatuto es una limitación legítima del derecho a la libertad de expresión contenido en la Primera Enmienda. (Tribunal Supremo de Georgia. 1973, p. 5).

Sin embargo, los precedentes cambiaron de manera repentina para favorecer la imagen, $y$ con la facilidad de contar con varias opiniones, dependiendo de los Estados, era mucho más factible que hubiera diferentes precedentes que apoyaran o contradijeran el derecho a olvidar o suprimir alguna información; avalando lo anterior, y mostrando el cambio hacia la protección de aquella información y la duda de que si todo se debería tratar por la Primera Enmienda, Francisco Leturia (2016) explica cómo un caso revalúa el precedente mismo que quedó en Cox, al afirmar que:

Un caso aún más interesante se originó en la sentencia que cuestionó la legitimidad de una publicación que hacía referencia a actividades homosexuales entre adultos y adolescentes acontecidos a mitad de los años 50, generando gran revuelo (una de las personas involucradas fue luego expulsada de la Academia de West Point). La sentencia consideró que el caso era muy distinto al precedente de Cox Broadcasting y de toda la jurisprudencia nacida a su amparo, señalando que en algunos casos el interés público era dudoso. Dado el giro que esta sentencia podía implicar frente a la tradicional comprensión de la primera enmienda, fue objeto de un recurso especial ante el Tribunal Supremo de Idaho ('rehearing'), la que validó tanto la publicación como los criterios de las instancias inferiores, reiterando las dudas sobre cómo el paso del tiempo podría afectar el interés público de un hecho, así como la dificultad de determinarlo. (Leturia, 2016, p. 95-96).

En el marco europeo, la tendencia fue igual hasta la llegada de la Segunda Guerra Mundial, ya que por medio de este acontecimiento histórico hubo una revelación de garantías y derechos especialmente para todas las personas; por lo tanto, se comenzó a hablar mucho más de la imagen misma y lo que la propaganda podría afectar o no en una situación en específico; luego de tanto hablar del tema, pero no concretar el concepto de derecho al olvido, sino en cambio una serie de escaramuzas frente a quién tiene más derecho frente a otros, se equilibraron y se resaltaron los de mayor peso. 
Todo cambia en los años 2013 a 2014. Ana Azurmendi (2015) relata cómo el derecho al olvido cobra más importancia y resurge en el entendido del derecho en la comunidad internacional, con epicentro en el mismo lugar donde había sido sepultado con sentencias que se acogían a la Primera Enmienda:

Entre los meses de junio de 2013 y junio de 2014, el derecho al olvido cobró un protagonismo inusual en los medios de comunicación y en los centros de poder político tanto de la Unión Europea como de Estados Unidos. Las filtraciones realizadas por Edward Snowden - un técnico de la Agencia Americana de Seguridad NSA (National Security Agency) - en junio de 2013, sobre el espionaje masivo de la NSA a gobiernos, instituciones y ciudadanos, causaron un gran impacto. Sobre todo, desde que se conoció la cooperación imprescindible de empresas de Internet y compañías de telecomunicaciones como Google, Yahoo, Microsoft, Facebook, Pal Talk, Skype, Apple y AOL, entre otras. (Azurmendi, 2015, p. 275-276).

En 2014, el Tribunal de Justicia de la Unión Europea dicta un fallo hito que terminó obligando a Google a sacar información del buscador, la cual afectaba a las personas que en un momento tenían un papel preponderante, y que es lesiva y afecta directamente muchos derechos. El principal protagonista de esta historia es Mario Costeja, un abogado que demanda a Google por publicar información que, entre otras cosas, afirmaba que él todavía debía unos dineros desde hacía mucho tiempo y desconocía su estado civil de soltero al decir que aún era casado. Por lo tanto, se presenta una consulta prejudicial que llega al Tribunal Europeo de un proceso que llevaban los tribunales españoles para evaluar qué decisión se debería tomar.

La sentencia del Tribunal de Justicia Europeo (2014) se puede entender en tres aspectos importantes, que terminan cambiando el rumbo y positivando el derecho al olvido; en primera medida, la indexación de datos si es un tratamiento efectivo de los mismos, toda vez que el motor de búsqueda decide qué información tiene mayor relevancia, pese a no ser la fuente primaria, y según el artículo 2, letra b), de la Directiva 95/46, el manejo de datos puede ser automático o no, sin importar que solo sea la vitrina en la que se exhibe esa información. Y el segundo aspecto que determina la sentencia del Tribunal Europeo es que si se debe o no borrar información por parte del motor de búsqueda y su obligación para retirar esos vínculos; y el centro del debate es el efecto multiplicador de los vínculos, que es la manera en la que el motor de búsqueda redirecciona y amplía la información. Al respecto la sentencia, según Ana Azurdmendi (2015), expone:

Efecto multiplicador en Internet que puede ser indeseable pero que, en muchos casos, convive con la publicación legítima de un contenido periodístico sobre una persona. No sería lógico eliminar una noticia veraz, por ejemplo, porque contenga datos personales, pero tampoco sería lógico que esa noticia fuera accesible siempre - años después de su publicación- con carácter universal. (Azurmendi, 2015, p. 287). 
El último evento que trata de regular el Tribunal y que es de importancia para esta investigación, es si ¿el simple capricho de una persona es suficiente para la eliminación por parte del motor de búsqueda de aquella información?, y la solución al respecto la expresó de nuevo Ana Azurdmendi (2015), al argumentar que:

La recomendación fundamental del informe es la limitación de la universalidad del derecho al olvido en función de los sujetos que solicitan el borrado (a quienes clasifica en tres niveles distintos de dificultad-facilidad para suprimir los datos requeridos: personas con proyección pública general, personas sin esa proyección y personas con proyección pública sólo en un ámbito determinado como directores de escuelas, funcionarios públicos, etc.); en función del contenido de la información de que se trate; y, finalmente, en función del territorio. En este sentido la recomendación más importante es que el derecho al olvido sólo se aplique en Europa y para los ciudadanos europeos. (Azurmendi, 2015, p. 291-292).

En conclusión, estos argumentos proporcionaron las bases fundamentales para que se interpretara correctamente la directiva antes mencionada, y por lo tanto diera pie para que se presentara una brecha entre aquello que se debería publicar o no. Según Jiménez y Ballesteros (2018), esta directiva logró en los comunicadores pensar que “[...] un instrumento demasiado poderoso en la medida en que podía potencialmente lesionar la libertad de expresión y el derecho del público a la información" (p. 11). Después de esta sentencia, más de quinientas mil solicitudes contra Google fueron efectivas para suprimir toda esa información.

Desde ese momento surgen muchas peticiones a gigantes corporativos encargados de ser buscadores de información, para suprimir aquella que afecta la imagen de una persona frente a la comunidad. Esto ayudó a que de cierta manera se originara la necesidad de legislar frente al tema y que la comunidad europea por fin hablara de ello.

Algo muy importante de esta directiva, es que definió quién es el directamente implicado y cuál es la información en redes sociales con este rótulo de "lesivas", este techo que se le atribuye a ciertas normativas, impide que no se entienda la norma y que se utilice para otros fines diferentes a los inicialmente propuestos. En consonancia con lo anterior, podemos afirmar que es importante en el marco normativo, ya que como se observa hay jurisprudencia en todo el globo terráqueo que habla del mismo tema, pero que por carecer de un marco normativo, varía la interpretación en la que se debería utilizar la aplicación al derecho al olvido.

Este suceso marca un antes y un después en toda la comunidad internacional, a tal magnitud que en el Tribunal Europeo se debate si el derecho al olvido es un derecho fundamental de las personas y se le pondera con otros derechos de igual o mayor magnitud; pero en este punto, volvemos al mismo interrogante que planteamos desde el comienzo: ¿Quién tiene el poder de retirar información de las redes?, ¿quién está legitimado para suprimirla de internet? Como hemos observado en este avance histórico, por regla general lo ha tenido el Estado, en muchas ocasiones el que fungía como máxima autoridad o simplemente si existe una división en quienes hacían de poder jurisdiccional, pero ¿el máximo implicado cuándo tiene esa potestad? $\mathrm{O}$ ¿es 
libre o autónoma del dueño del motor de búsqueda como Google? Son los dilemas que rodean el derecho al olvido, pero debe haber un trámite procesal para que se reconozca ese derecho, en el que alguien tiene la potestad de administrar esa justicia sin perjuicio de quién acciona el mismo, que en muchas ocasiones es el directamente afectado.

\section{Actualidad en el ordenamiento jurídico colombiano}

No es un secreto que el epicentro de nuevos derechos positivos es Europa, los que a su vez traspasan las barreras del viejo continente hacia otros países que siguen sus tradiciones y linajes jurídicos. Naciones como Argentina, Chile, Brasil y Colombia, fueron permeados de muchos preceptos europeos, uno de los varios ejemplos es el objeto mismo de esta investigación. El derecho al olvido, cuando en 2013 comienza a tener más revuelo mediático, hace pensar a los demás países de Sudamérica si hay que reconocer un derecho de supresión de información por las redes y plataformas de internet; esto da inicio a un proceso "camaleónico", en el que cada Estado lo adapta según su ordenamiento jurídico. Varios países se encaminan por esa directriz del derecho al olvido como norma o como doctrina, pero Colombia toma una tendencia de desarrollarlo por medio de jurisprudencia, al buscar, por medio de las altas cortes, interpretarlo con lo ya existente.

Colombia maneja en su ordenamiento un tema denominado el "Habeas data", que según Enrique Pérez-Luño (2017) es "que tengas los datos", "que vengan los datos" o "que tengas los registros"; es decir, "tomar conocimiento de datos propios en poder de otro" (p. 113). La Constitución Política colombiana (1991) reconoce dentro de los derechos fundamentales el derecho a la protección de datos y consagra en su articulado 15, que:

Todas las personas tienen derecho a su intimidad personal y familiar y a su buen nombre, y el Estado debe respetarlos y hacerlos respetar. De igual modo, tienen derecho a conocer, actualizar y rectificar las informaciones que se hayan recogido sobre ellas en los bancos de datos y en archivos de entidades públicas y privadas. En la recolección, tratamiento y circulación de datos se respetarán la libertad y demás garantías consagradas en la Constitución. La correspondencia y demás formas de comunicación privada son inviolables [...]. (Constitución Política de Colombia, 1991, artículo 15).

Lo anterior eleva a un grado supralegal el tema de la información personal, originando así que el habeas data tiene un trámite por la vía excepcional de la tutela, un mecanismo que se utiliza para garantizar derechos fundamentales cuando estos han sido vulnerados. Al respecto, la Honorable Corte Constitucional (2018), citando la jurisprudencia anterior, ha dicho que:

Este comporta el derecho a obtener información personal que se encuentre en archivos o bases de datos, la posibilidad de ser informado acerca de los datos registrados sobre sí mismo y la facultad de corregirlos, la divulgación de datos ciertos y la prohibición de manejar tal información cuando existe una prohibición para hacerlo. En este sentido, la Corte concluyó que ' [...] tanto el habeas data como la intimidad encuentran su razón de ser y su fundamento último en el ámbito de autodeterminación y libertad que el ordenamiento jurídico reconoce al sujeto como condición indispensable para 
el libre desarrollo de su personalidad y en homenaje justiciero a su dignidad'. (Sentencia T-077, 2018. Corte Constitucional de Colombia).

Como se puede observar, ya existe una consagración sobre protección de datos, es más, en Colombia un año después de la promulgación de la Constitución ya se hablaba de la protección de datos por su carácter constitucional que le otorgaba el habeas data. Esto quiere decir que pese a que el concepto de "derecho al olvido" se acunó después de 15 años al otro lado del océano, en nuestro ordenamiento jurídico ya existía un procedimiento para garantizarlo y protegerlo; sin embargo, ¿quién es el titular de ese derecho?, ¿cuál sujeto es el legitimado para accionar los mecanismos antes mencionados para garantizar o proteger ese derecho? La Corte Constitucional en una sentencia anterior nos presenta la respuesta, al argumentar que:

[...] es titular a priori de este derecho y el único legitimado para permitir la divulgación de datos concernientes a su vida privada. Su finalidad es la de asegurar la protección de intereses morales; su titular no puede renunciar total o definitivamente a la intimidad pues dicho acto estaría viciado de nulidad absoluta. (Sentencia T-441, 1992, Corte Constitucional de Colombia).

Queda claro que este derecho es garantizado y postulado en una norma, que es la más importante en un ordenamiento, garantizado en el área civil o comercial, en casos específicos, cómo borrar el historial crediticio y la mora de obligaciones o el cambio de información personal, cuando exista el debido procedimiento en el estado civil. Sin embargo, este derecho no es absoluto en todas las ramas de un ordenamiento jurídico, toda vez que en unos casos la persona sí puede disponer de la información y en otros casos priman otros derechos y garantías, por lo tanto: ¿En qué casos sí se puede y en qué casos no?

\section{Problemática con el Derecho Penal}

El Derecho Penal, última ratio de nuestro ordenamiento jurídico, al que solo y exclusivamente se acude a esta rama cuando no hay otra forma de castigo o sanción en otras ramas del Derecho, respecto a que una de las sanciones más comunes es la privación del derecho fundamental de la libertad, aquel no contempla el derecho del habeas data como posibilidad de garantizar el manejo de información de las personas. Esta negativa del Derecho Penal para consagrar un "Habeas data penal" va ligada a varios factores, que pueden causar controversia en muchos casos, en los que se ponen en una balanza ciertos preceptos: la memoria o el olvido, la publicidad de información o la supresión de la misma o simplemente quedar en el pasado o avanzar hacia el futuro.

Se puede justificar que en el Derecho Penal no se maneje el derecho al olvido por muchos factores; el primero, sin duda alguna, es el principio de publicidad que opera en el proceso penal como tal; todo proceso debe ser público salvo excepciones, eso conlleva a que conozcamos aspectos generales del proceso, como quién es el imputado, acusado o condenado, dependiendo de cada etapa o que sepamos por cuáles tipos penales el ente acusador lleva el proceso; lo 
anterior, es en un caso en el que estamos en medio de un proceso penal, en el que existe la posibilidad del beneficio de la duda, y pese a que hablamos de la presunción de inocencia, los juicios paralelos ya están condenando al que funge como sujeto activo.

En estos casos, sí se tiene como derecho que las personas conozcan y sepan los procesos que se llevan en la administración de justicia. Pero si ya se dictó sentencia absolutoria, y se paga la condena, ¿esa información debe seguir en las redes? o ¿debería haber un "habeas data penal"?; estas son las dudas e interrogantes que se suscitan frente a una persona que debe cargar con el yugo de un juicio paralelo.

Lo anterior desencadena una serie de problemáticas desde el punto de vista de la teoría penal, sus alcances y el desarrollo jurisprudencial, y deja una serie de postulados en los cuales podríamos darle un matiz negativo de lo importante que es olvidar para avanzar en una sociedad, todo ello explicado desde la legitimidad que tiene una persona de poder hacer con su información lo que desee, cuando no debe nada a nadie y quiere olvidar algunas cosas.

\subsection{Finalidad de la pena}

La pena es la sanción jurídica que se le otorga al sujeto que comete una conducta punible; sin embargo, va más allá como concepto, según Elba Cruz y Cruz (2017): "La punibilidad es un elemento secundario del delito que consiste en el merecimiento de una pena, en función o por razón de la comisión de un delito; dichas penas se encuentran establecidas en nuestro Código Penal" (p. 230). Por lo tanto, la pena llega a ser el complemento de cometer un delito; en palabras de Miguel Polaino (2013): la pena "equivale a la susceptibilidad, necesidad y merecimiento de la realización del injusto típico y culpable” (p. 179). El Estado es, por lo tanto, el único que como derecho subjetivo tiene esa capacidad de establecer una pena respecto a ese ius puniendi con todos los limitantes que un Estado Social de Derecho debe garantizar.

La pena en sí misma es una herramienta para que en el caso de un incumplimiento a una norma jurídica penal, se tenga una consecuencia que dé como resultado una coacción que a su vez sancione, pero que también cumple con unas finalidades, ya que la misma no es solo la respuesta del Estado a un injusto únicamente, sino una respuesta profunda y compleja por parte del Estado, la que va más allá de un interés expiativo. La Corte Constitucional explica al respecto:

En este orden de ideas, la circulación restringida de la condena penal refleja el fundamento humanista del ordenamiento penal, la resocialización y reinserción al tejido social. El marco constitucional brinda una especial protección para que se le permita, a quién ya saldó sus deudas con la justicia, no sufrir estigmatizaciones ni señalamientos de carácter discriminante en razón a su condena pasada, sobre la cual los jueces de la República ya indicaron que se dio cumplimiento y, por lo tanto, dicha persona logró uno de los objetivos que era la reincorporación a la sociedad. (Sentencia T-098 de 2017, Corte Constitucional de Colombia, 2017). 
La pena, por consiguiente, no busca que la persona cargue siempre con el juicio de la sociedad, sino que además de expiar su conducta pueda resocializarse, pero surgen las preguntas: ¿La información de alguien con respecto a la comisión de un delito que se encuentre en redes sociales después de haber pagado la condena, puede generar una resocialización efectiva? $\mathrm{O}$ ¿después de mucho tiempo se debe conocer que alguien es culpable de un delito, pese a que ya entendió y le cumplió al ordenamiento jurídico aceptando su sanción?

Por consiguiente, no se tiene una garantía de que la persona se resocialice, cuando la sociedad tenga serios prejuicios sobre aquel; esto creará un estado que obliga al antiguo "reo" a vivir con un pecado que ya pagó y a tratar de superarlo o aun peor, volver a delinquir porque ya la sociedad lo ha tildado de esa manera.

\subsection{El dilema entre indulto y amnistía}

Muchas veces, los procesos no terminan siempre con una absolución o una condena, ni siquiera la persona a la que se le lleve un proceso en curso y se encuentren todos los elementos materiales probatorios y evidencia física para que sea condenado, termine entonces con una pena. En este momento es que entra el indulto y la amnistía, dos figuras que tienen mucha trascendencia en el Derecho Penal y un recorrido histórico casi tan amplio como lo es el mismo ius puniendi; el primero, según el profesor Lorenzo Morillas (2016), dice que:

Se trata de una manifestación de la prerrogativa de gracia por la que se extingue la responsabilidad criminal, mediante la remisión total o parcial de la pena a que hubiese sido condenado un sujeto, y aún no hubiese cumplido, o mediante su conmutación por otra de menor gravedad, atendiendo a razones de justicia, equidad o utilidad pública. (Morillas, 2016, p. 356).

En este orden de ideas, podemos argumentar que el indulto es la "gracia" o el perdón de la pena misma, en el que por razones más importantes que la punibilidad del sujeto, se le otorga ese beneficio.

La amnistía a diferencia del indulto se caracteriza porque principalmente es el olvido de la pena, o que de cierta manera el Estado no piense más en ese delito y desista de la acción penal que conlleva la conducta punible. Al respecto, y al seguir la tesis de Lorenzo Morilla (2016) frente a la comparativa de uno u otro, afirma que:

Así, mientras que el indulto supone el perdón de la pena, la amnistía supone el perdón u olvido absoluto del delito; el indulto afecta a una persona concreta, y la amnistía, a un conjunto de personas, constituyendo en esta última, la pluralidad, un elemento determinante en la misma; el indulto, no extingue la responsabilidad civil derivada del delito, y la amnistía, sí. (Morillas, 2016, p. 356).

De acuerdo a estas precisiones, podemos afirmar que la amnistía es la figura del Derecho Penal para que el Estado olvide un delito; sin embargo, ese olvido: ¿opera de manera integral?; la población como elemento fundamental del Estado en la teoría clásica del mismo, ¿elimina esa información y la olvida? No existe entonces una amnistía real, sino una simple formalidad de no 
continuar con el accionar penal. Ni siquiera el Estado, aun con la herramienta para olvidar una pena, sea después o antes de la sentencia, no puede obligar a sus miembros a no pensar en ello, lo cual deja obsoleta la figura frente a su concepto penal.

De nada sirve que el Estado posea una herramienta formal para tratar de olvidar, si solamente es este el que olvida. ¿Dónde queda la efectividad de una justicia transicional? ¿Dónde queda la oportuna intervención del Estado en casos de reconciliación?, y no es que busquemos acogernos a un Estado intervencionista tipo "gran hermano" que controle todas las situaciones de sus conciudadanos, sino que si se quiere una efectiva utilización de la amnistía, se deben intervenir las redes para que no sigan difundiendo dicha información.

\subsection{Pasado judicial, principio de publicidad y la obstinación de no querer dejar las cosas en el pasado}

Uno de los pilares en la principialística del Derecho Penal y de la Teoría General del Proceso es el principio de publicidad, que es la posibilidad de que las partes y la comunidad conozcan de un proceso. Esto ayuda a la trasparencia del mismo y obedece a una necesidad de que toda actuación judicial se conozca. Todo este argumento es justificable si estamos inmersos en el curso de un proceso, pero: ¿Y si ya hay sentencia condenatoria o absolutoria? En la Sentencia T-512 de 2016 de la Corte Constitucional se reitera lo importante que es esa información, y el carácter privado de manera relativa, al argumentar que:

La información sobre los antecedentes penales que reposan en bases de datos debe someterse a un riguroso tratamiento que respete los principios de finalidad, necesidad, utilidad y circulación restringida. Este conjunto de principios define la senda por la cual se debe conducir la administración de dicha información y permiten fijar límites y competencias precisas para quienes acceden y administran las bases de datos sobre antecedentes penales. Como lo indicó la Corte, este conjunto de principios permite a la vez garantizar los derechos y libertades de los sujetos titulares de la información: 'En términos normativos, son la concreción legal y jurisprudencial del mandato del inciso $2^{\circ}$, del artículo 15, de la Constitución que establece que [e]n la recolección, tratamiento y circulación de datos se respetarán la libertad y demás garantías consagradas en la Constitución'. (Sentencia T-512 de 2016, Corte Constitucional de Colombia).

La Corte habla de una circulación restringida. Sin embargo, podemos observar que las empresas privadas hacen una recopilación que, si bien no es constitucional, debe haber una necesidad para que esa información salga a luz.

A renglón seguido, la Sentencia cita la Constitución al afirmar que: “Artículo 248. Únicamente las condenas proferidas en sentencias judiciales en forma definitiva tienen la calidad de antecedentes penales y contravencionales en todos los órdenes legales". Por lo tanto, la Constitución ya consagra un tipo de sentencias con un efecto específico, a través de las sentencias absolutorias. 
La página oficial de la Rama Judicial (s.f.) tiene un acápite de consulta de procesos, en la que se puede examinar cualquier proceso en todo el país, sin importar la cuantía, solamente escribiendo el lugar y el nombre; la única salvedad que se hace es que no se va a conocer el contenido mismo del proceso sino las generalidades del mismo, pero con la posibilidad de que uno pueda buscar los procesos en el juzgado y crear una base de datos.

Muchas empresas aprovechan lo anterior, y basadas en el principio de publicidad, ahondan en esto y crean una base de datos al estilo "Big data", y reúnen toda esa información para ofrecerla como catálogo a cualquier interesado que quiera lograr una remuneración pagando una membresía en la página objeto de la misma; esta página no discrimina si son procesos terminados o en curso; por lo tanto, el rezago de un proceso del que ya se pagó la condena o simplemente si se sale absuelto, quedará ahí, a la interpretación de un juicio paralelo social. Cualquier persona que pagué cincuenta mil pesos colombianos, en promedio, puede acceder a toda la información de un proceso, incluida una sentencia absolutoria o condenatoria. Esto va en contra de un precepto constitucional, porque estaríamos utilizando un antecedente que no es el que la Carta Magna consagra, y nos preguntamos: ¿Dónde queda el derecho al olvido?; una persona que si bien tenga un proceso y que a la luz de la justicia sea inocente, quedará marcada por esa información que fácilmente se puede conseguir.

El caso Colmenares es el ejemplo más claro de cómo se sostiene un antecedente y pese a que la información de la propia página de la Rama no la pueda tener pública, la sentencia sí es objeto público; por más de que la administración de justicia declare de manera expresa en todas las instancias posibles que las acusadas son inocentes, el juicio público será contundente para condenarlas. Ante esto, es mucho más fácil crear herramientas que se apliquen al derecho al olvido, amparando un derecho constitucional, que buscar el perdón y la credibilidad en la Rama Judicial.

\subsection{Sanción al delito desde el punto de vista de la teoría funcionalista y la aplicación del derecho al olvido}

Muchas teorías han rodeado el Derecho Penal, y son coetáneas al avance histórico; a mayor desarrollo de las teorías y las ciencias humanas, más compleja y estructurada la teoría penal, esto justificado también en que al ser el derecho una ciencia humana, no hay situaciones y leyes perfectas o exactas; por lo tanto, debe existir una constante mutación del mismo, sino este quedaría obsoleto. Esto ha dado paso a teorías kantianas como el "Casualismo", como lo fue la teoría clásica o teorías netamente apegadas a lo que dice la Ley, como las que profesaba Enrico Ferri y hasta el mismo Jorge Eliécer Gaitán.

Sin embargo, hay que hacer hincapié en dos teorías importantes y a decir verdad las últimas a lo largo del avance académico de la teoría del delito penal y la estructura dogmática del Derecho Penal; la primera es el finalismo, importante teoría porque nuestro ordenamiento 
jurídico la maneja y resuelve muchos problemas que a lo largo de la historia habían embargado el derecho jurídico penal. Según Elba Cruz (2017):

Debido a ello es que se trata de construir el derecho sobre la denominada naturaleza de la cosa, empero, enfatizando las nuevas direcciones psicológicas, principalmente, la 'psicología del pensamiento.' Como consecuencia sostiene que el derecho penal está vinculado a la estructura final de la acción; luego entonces la acción ya no es concebida causalmente, sino finalmente. (Cruz, 2017, p. 258).

Por consiguiente, es la pena la sanción jurídica por cometer el delito con todos sus elementos dogmáticos; sin embargo, como se mencionó, la pena tiene una finalidad retributiva, preventiva y resocializadora, y esto en relación al derecho al olvido se puede observar que no cumple las funciones mismas de la pena, la no aplicación del habeas data penal. Pero al tener tantas revaluaciones, la teoría Finalista se vio en la necesidad de tener una nueva teoría que pudiera segmentar y solventar los problemas que acarreaban las antecesoras, y es entonces cuando nace una nueva, basada en el rol que cumplen las personas en la sociedad.

El funcionalismo, según la traducción que hace Manuel Cancio de Günther Jakobs (1998) sobre la teoría penal y el rol que cumple en una sociedad, en la cual desempeñamos funciones, se habla de que el delito es una contradicción a las normas de la sociedad; es decir, el comportamiento de una persona que pertenece a la sociedad es contrario a la norma, defraudando las expectativas que el Estado le había confiado, lesionando así la vigencia de la norma, y la pena es, por consiguiente, la respuesta del Estado frente a esa acción para estabilizar de nuevo ese sistema normativo social, lo cual, en pocas palabras, sería la reinterpretación de la dialéctica hegeliana en la que una tesis sería la acción infractora; una antítesis, la acción del Estado en el intento de restablecer su vigencia normativa y la síntesis sería la pena per se.

En ese orden lógico, bajo la teoría funcionalista, quien tiene el interés o está llamado a responder con el ius puniendi de la acción de la persona, es el Estado, para así poder reafirmar la vigencia de la norma; es decir, la persona que comete el delito, termina siendo merecedor de una sanción del Estado, no otra persona, ni la sociedad ni otro actor distinto. Por lo tanto, si se paga la pena de acuerdo a la sanción que el Estado impone, se cumple la función, se estabiliza la norma y envía un mensaje a la sociedad de que la norma sigue vigente. El Estado no tiene otra finalidad diferente para recordar que la persona cometió el delito o difundir información del mismo después de haber pagado la condena, porque con la sola sanción ya se restableció el ordenamiento.

El sujeto activo no le debe nada a la víctima, por cuanto no es un juicio de la sociedad o de un reproche mismo, sino un incumplimiento o desconocimiento del orden legal. Es por esto que después de que la condena sea pagada, no hay necesidad de conservar la información por la cual Estado fundamentó la sanción, porque ya se cumplió la finalidad primaria, base de la teoría. 


\subsection{La revictimización de personas que prefieren que olviden en vez de recordar}

En el marco de muchos conflictos, se establecen centros históricos que tienen como función principal crear una conciencia de memoria, para que en un futuro no vuelvan a suceder dichos hechos. Las iniciativas se tornan conmovedoras y demasiado altruistas, por la necesidad de que algunos sucesos no se repitan en ningún momento. Saida Mantilla (2015), en un artículo de investigación sobre la revictimización como causal del silencio de la víctima, expresa que:

Es pues de vital importancia prestar mayor atención a las actitudes negativas del profesional al momento de intervenir en la denuncia que realiza la víctima, ya que la victimización desencadena una serie de alteraciones en la conducta de las víctimas a nivel psicosocial, originándose así la revictimización por parte del sistema jurídico penal. (Mantilla, 2015, p. 6).

Lo anterior, desde un punto de vista generalizado; sin embargo, la misma autora citando otros autores en el mencionado artículo dice que la situación se agrava en los delitos sexuales, aquellos que no solo son la violencia misma que causa, sino la repercusión personal y social que ellos generan.

En el caso de los delitos sexuales, algunos autores como Marchiori, Biodo y Fortete sostienen que en la mayoría de estos casos la agresión sexual, indirectamente conlleva a que la víctima sea revictimizada por los operadores jurídicos, exponiéndose a sufrir un mayor daño que el proporcionado por el delito en sí. (Mantilla, 2015, p. 6).

Como podemos observar, termina siendo perjudicial la revictimización. En muchos casos la víctima ni siquiera quiere la condena del sujeto activo, para sentir una retribución por el dolor causado por el delito. Sin embargo, hay eventos en los que la víctima realmente quiere pasar la página, dejar a un lado esa situación, no todos quieren ser las víctimas de esos delitos, sino que buscan olvidar, para poder seguir la vida corriente.

No olvidar, no solo involucra al victimario, sino a la persona que es víctima en un delito y no solo en delitos sexuales sino en cualquier delito; es más, siendo consanguíneo o afín de la víctima, tampoco es grato recordar ciertas situaciones. Esa aplicación del olvido debe ser obligatoria por parte del Estado y para los administradores de justicia, como expresa Saida Mantilla (2015): "Se hace necesario velar por la integridad de las víctimas, por sus derechos y acompañamiento antes, durante y después del evento agresivo, garantizándoles con ello el cuidado y protección que estas demandan del sistema jurídico-penal” (p. 11).

Si nuestro sistema procesal penal garantiza la no utilización de algunas pruebas por no ser admisibles, el artículo 376 de nuestro Código Penal (2018) consagra en su literal que "que exista peligro de causar grave perjuicio indebido". En una interpretación doctrinal de dicho texto, el perjuicio indebido es referente de dos factores: integridad de un testigo, y la revictimización; este último más desarrollado, tiene como finalidad que la víctima no tenga, innecesariamente, que volver a hablar del tema o que en un debate de juicio oral se vean menoscabados sus derechos. Si se consagra esto en el marco de un proceso penal, ¿por qué no podemos consagrarlo 
cuando ya se ha terminado el mismo? o ¿al Estado le queda demasiado complicado no generar una doble victimización en su población?

\section{Conclusión}

La realidad es que Colombia es una nación con la tendencia de olvidar momentos y situaciones importantes. Hoy puede surgir una noticia que sea tendencia y mañana quizás la gente no se acuerde de esas situaciones y esto suele suceder en cualquier grupo social; por ejemplo, personas de una universidad olvidan el ridículo que hacen al responder a algo sin sentido o una ciudad puede obviar de su recuerdo a un conductor que cometa una riña en plena plaza pública y que haya sido tema de conversación por el multiplicador de información, que son las redes sociales. Pero si las personas olvidan rápido, ¿qué es más importante, recordarle situaciones o dejarlas en el pasado y que se pierda esa información en el olvido?

Es importante ayudar a que la sociedad avance, la opción no es afectar el futuro al traer hechos del pasado al presente, y muchas veces el derecho a la memoria afecta de lado y lado. En el Derecho Penal, que se le recuerde a la víctima que fue sujeto pasivo de un delito, es igual de tormentoso que recordárselo a alguien que ya pagó su condena y aun así, carga con la cruz del escarnio público. De nada sirve que una persona quede privada de su libertad por 20 años para que salga a la calle y todo el mundo se lo recuerde, y aun peor, no tiene sentido que un presunto delincuente sea llevado a la justicia, sea absuelto, pero todavía así, por la falta de credibilidad de las instituciones mismas, la sociedad lo rechace porque crea que debió ser condenado.

Muchas variables pueden dilucidarse por las consecuencias que trae el rechazo público, pero ¿es viable cercenar un derecho tan importante como el de la memoria?, ¿hay necesidad de suprimir información para que una persona pueda integralmente resocializarse?

No sería correcto afectar un derecho por proteger otro; sin embargo, muchas de las soluciones que se presentan son aquellas que establecen cuál es más necesaria y cuál se puede desmeritar dependiendo la importancia, siendo así una manera "poética" de definir que no estamos ubicándolas en una balanza, pero tenemos que mirar cuál pesa más que otra.

España fue pionero en positivizar el derecho al olvido dentro del marco de los derechos y potencialmente derecho fundamental per se o conexo con otros derechos; pese a que solo han pasado más de cuatro años desde que se habló del tema, ya han dado una solución que el mismo Tribunal Europeo profirió en su momento, y tal vez esta es la solución más salomónica que se puede otorgar para defender todos los derechos en cuestión que se suscitan en este debate de olvidar o recordar mal.

Lo anterior queda mejor explicado en los argumentos de Teresa Rodríguez (3 de marzo, 2016) cuando expresa que, si bien es cierto, la fuente primaria no son los motores de búsqueda, pero estos le dan visibilidad a la información, y pese a que hay información que sea veraz, puede que no sea pertinente, por lo tanto afecta a las personas, pero así ayudamos a que lo hagamos invisible, ya que luego genera un conflicto entre varios derechos, como el derecho a la 
información; el fin último es que creemos un equilibrio de intereses y derechos pactados con la sociedad: "Construyendo un red de personas en la que nos veamos reflejados y nos reconozcamos y los otros nos reconozcan también [...] y por supuesto, ser vosotros los que decidáis qué queréis recordar y qué queréis olvidar” (s. p.), porque al fin y al cabo es la persona la que elige qué le gustaría que recordaran de sí misma, y no la comunidad.

Lo anterior, se puede trasladar a nuestro ordenamiento en la garantía que se consagra en la dignidad humana, que según Manuel Quinché (2009):

a) La dignidad como ejercicio de la autonomía personal, patente en el diseño del propio plan de vida, que la Corte ha entendido como 'vivir como quiera' y que se ha traducido en protecciones concretas, como la de la despenalización del consumo de sustancias psicoactivas, la decisión sobre las preferencias sexuales que se quieran, el derecho a morir dignamente, el derecho a escoger profesión u oficio, etc. b) La dignidad como condiciones materiales de existencia, que la Corte entiende como 'vivir bien', línea esta que ha permitido indicar niveles de bienestar en las cárceles, la protección por tutela de los derechos a la salud y la integridad personal, la preservación del mínimo vital, la protección a las peticiones de reconocimiento de pensión de jubilación y otras similares. c) La dignidad como intangibilidad de la integridad física y moral, que la Corte entiende como 'vivir sin humillaciones', que ha permitido impedir penas irredimibles sobre los inimputables, así como castigos infamantes a menores de edad, limitar la servidumbre en las relaciones laborales y proteger a las personas de la tercera edad o a las minorías sexuales. (Quinché, 2009, p. 87-88).

No hay nada más atentatorio a estos tres preceptos que el flagelo de recordar información de una persona que ella no quiera tener y recordar, ya que no se lograría "vivir bien", en aras de la tranquilidad, no se viviría como se quiere, porque la finalidad es que no esté esa información en redes y se corra el riesgo de vivir con humillaciones por causa de la permanencia de esta en la sociedad.

La solución es sencilla, y no requiere irnos al juicio de ponderación. La memoria es un derecho que deberíamos tener siempre; sin embargo, hay cosas que se pueden olvidar con el tiempo o por voluntad propia. Por lo tanto, es posible aplicar el derecho al olvido, solamente bajándole el tráfico a aquello que afecta el derecho a un futuro distinto, no hay necesidad de eliminarlo, que esté en las redes, y quien lo necesite la busque haciendo un ejercicio más arduo, pero sin ser la primera página que aparezca cuando se requiera saber de alguien.

Sin embargo, sobre el tema hay mucho que tratar, sobre todo en nuestro ordenamiento jurídico que ha sido acérrimo a garantizar otros derechos, en vez del derecho al olvido, como expresó Bosco Cámara:

El debate estaba servido: por un lado, el derecho de la sociedad a conocer asuntos de trascendencia o interés general y juzgarlos es necesario para conformar la opinión pública. Por otro lado, se plantea si ese derecho a conocer abarca incluso hechos sucedidos hace tiempo que ya han perdido interés. Dicho de otro modo ¿todas las noticias de una hemeroteca digital cumplen la función de conformar la opinión pública? (Bosco Cámara, 2015, s. p.). 
La labor más importante es lograr que una sociedad perdone; sin embargo, es un trabajo de décadas y hasta de siglos, porque la misma está matizada con la venganza y el rencor, pero esto no quiere decir que se pueda alcanzar en un futuro; mientras ocurre, la idea es enseñar y garantizar el olvido de aquello que no nos deja avanzar como personas, comunidad y sociedad.

\section{Referencias}

Azurmendi, A. (2015). Por un 'derecho al olvido' para los europeos: aportaciones jurisprudenciales de la Sentencia del Tribunal de Justicia Unión Europea del caso Google Spain y su recepción por la Sentencia de la Audiencia Nacional española del 29 de diciembre de 2014. Revista de Derecho Político, (92), 273-310. Recuperado de https://doi.org/10.5944/rdp.92.2015.14428

Cámara Pellón, B. (1 de junio de 2016). Derecho al olvido vs. Derecho a la Memoria. La Toga. 192. Recuperado de https://www.revistalatoga.es/derecho-al-olvido-vs-derecho-a-la-memoria/

De Castro-Camero, R. (2000). El crimen maiestatis a la luz del senatus consultum de Cn. Pisone Patre. Sevilla, España: Universidad de Sevilla.

Constitución Política. (1991). Bogotá, Colombia: Editorial Legis.

Directiva 95/46/CE Parlamento Europeo y del Consejo. (24 de octubre de 1995). Diario Oficial, No. L 281. Recuperado de https://eur-lex.europa.eu/legal-content/ES/TXT/HTML/?uri=CELEX:31995L0046\&from=EN

Cruz y Cruz, E. (2017). Teoría de la ley penal y del delito. México: IURE Editores.

Günther, J. (1998). Sobre la teoría de la pena (Trad. Manuel Cancio Meliá). Bogotá, Colombia: Universidad Externado de Colombia. Recuperado de http://perso.unifr.ch/derechopenal/assets/files/ articulos/a_20170508_03.pdf

Jiménez-Castellanos \& Ballesteros, M. I. (2018). El derecho al olvido digital del pasado penal (Tesis doctoral). Universidad de Sevilla, Departamento de Derecho Constitucional, Sevilla. Recuperado de https://idus.us.es/bitstream/handle/11441/75092/TESIS\%20\%20EL\%20DERECHO\%20AL\%20OLVIDO\%20DIGITAL\%20DEL\%20PASADO\%20PENAL.pdf?sequence=1\&isAllowed=y

Leturia I., F. J. (2016). Fundamentos jurídicos del derecho al olvido. ¿Un nuevo derecho de origen europeo o una respuesta típica ante colisiones entre ciertos derechos fundamentales? Revista Chilena de Derecho, 43(1), 91-113. Recuperado de http://dx.doi.org/10.4067/S0718-34372016000100005

Mantilla, S. (2015). La revictimización como causal del silencio de la víctima. Revista de Ciencias Forenses de Honduras, 1 (2), 4-12. Recuperado de http://www.bvs.hn/RCFH/pdf/2015/pdf/RCFH1-2-2015-4. pdf

Morillas Cueva, L. (2016). La pena de prisión entre el expansionismo y el reduccionismo punitivo. Madrid, España: Editorial Dykinson.

Padró, J. (1999). Historia del Egipto faraónico. Madrid: España: Alianza Editorial.

Pérez-Luño Robledo, E. C. (2017) El procedimiento de Habeas Data: El derecho procesal ante las nuevas tecnologías. Madrid, España: Editorial Dykinson.

Platero Alcón, A. (2016, enero-junio). El derecho al olvido en internet. El fenómeno de los motores de búsqueda. Opinión Jurídica, (15), 29, 243-260. Recuperado de https://dialnet.unirioja.es/descarga/ articulo/5505806.pdf 
Polaino Navarrete, M. (2013). Lecciones de Derecho Penal. Parte General (Tomo II). Madrid, España: Editorial Tecnos.

Quinché Ramírez, M. F. (2009). Derecho constitucional colombiano de la Carta de 1991 y sus reformas ( $3^{\mathrm{a}}$ ed.). Bogotá, Colombia: Universidad del Rosario.

Rama Judicial Colombia (s.f.). Consulta de procesos. Recuperado de https://consultaprocesos.ramajudicial.gov.co/procesos/bienvenida

Rodríguez de las Heras, T. (3 de marzo de 2016). El derecho al olvido | TEDxUPValència [Archivo de video] Recuperado de https://www.youtube.com/watch?v=FkjMaJ8aNQA

Ros Gil, D. (2015). Laedere Verbis. El daño causado con la palabra y su represión en la antigua Roma. (Tesis Doctoral). Universidad de Valencia. Valencia, España. Recuperado de https://core.ac.uk/download/pdf/71052382.pdf

Sentencia T-512 (2016). Corte Constitucional de Colombia. Magistrado Ponente: Luis Ernesto Vargas Silva. Recuperado de https://www.corteconstitucional.gov.co/relatoria/2016/t-512-16.htm

Sentencia T-098 (2017). Corte Constitucional de Colombia. Magistrado Ponente. Luis Ernesto Vargas Silva. Recuperado de https://www.corteconstitucional.gov.co/relatoria/2017/T-098-17.htm

Sentencia T-077 (2018). Corte Constitucional de Colombia. Magistrado Sustanciador: Antonio José Lizarazo Ocampo. Recuperado de https://www.corteconstitucional.gov.co/relatoria/2018/T-077-18.htm

Tribunal Supremo de Georgia. (5 de septiembre del 1973). Cox Broadcasting Corp. v. Cohn. Recuperado de https://casetext.com/case/cox-broadcasting-corporation-v-cohn-8212-938

Tribunal Supremo Federal. (9 de agosto de 1956), Jenkins v. Dell Publishing Company, 143 F. Supp. 952 (WD Pa. 1956). Recuperado de https://law.justia.com/cases/federal/district-courts/ FSupp/143/952/1417669/

Tribunal de Justicia Europeo (13 de mayo de 2014). Sentencia del Tribunal de Justicia (Gran Sala) Recuperado de https://www.abogacia.es/wp-content/uploads/2014/05/Sentencia-131-12-TJUE-derecho-al-olvido.pdf

\section{Bibliografía recomendada}

Günther, J. (2005). ¿Cómo protege el Derecho penal y qué es lo que protege? Contradicción y prevención; Protección de bienes jurídicos y protección de la vigencia de la norma. En Los desafíos del Derecho penal en el siglo XxI: Libro homenaje al profesor Dr. Günther Jakobs. Lima, Perú: Ara Editores.

Peré, S. C. (2015). El reconocimiento del derecho al olvido digital en España y en la UE. Madrid, España: Editorial Bosch. Recuperado de http://www.wke.es/MK/PDF/El-reconocimiento-del-derecho-alolvido-digital-en-Espana-y-en-la-UE/files/assets/common/downloads/publication.pdf

Sentencia T-441. (1992). Corte Constitucional de Colombia. Magistrado Ponente: Alejandro Martínez Caballero. Recuperado de https://www.corteconstitucional.gov.co/relatoria/1992/t-441-92.htm 